\title{
MicroRNA-22 regulates autophagy and apoptosis in cisplatin resistance of osteosarcoma
}

\author{
CHEN-YANG MENG ${ }^{*}$, ZHEN-QUN ZHAO*, RUI BAI, WEI ZHAO, YU-XING WANG, \\ LIANG SUN, CHAO SUN, WEI FENG and SHI-BING GUO
}

\begin{abstract}
Department of Orthopedic Surgery, Second Affiliated Hospital of Inner Mongolia Medical University, Hohhot, Inner Mongolia 010030, P.R. China
\end{abstract}

Received December 4, 2019; Accepted July 20, 2020

DOI: $10.3892 / \mathrm{mmr} .2020 .11447$

\begin{abstract}
Osteosarcoma (OS) is a primary malignant tumor of bone tissue. Effective chemotherapy may improve the survival of patients with OS. MicroRNAs (miRs) serve significant roles in the regulatory function of tumorigenesis and chemosensitivity of different types of cancer. miR-22 has been revealed to inhibit the proliferation and migration of OS cells, as well as increasing their sensitivity to cisplatin (CDDP). The mechanisms of action behind the functions of miR-22 in OS drug resistance require investigation. Therefore, in the present study, the human OS cell lines (MG-63, U2OS, Saos2 and OS9901) and a drug-resistant cell line (MG-63/CDDP) were cultured. Cell proliferation, apoptosis and autophagy assays were performed to investigate the proliferation, apoptosis and autophagy of cell lines transfected with miR-22 mimic. Reverse transcription-quantitative polymerase chain reaction and western blot analysis were performed to investigate the expression levels of associated genes. The results revealed that miR-22 inhibited the proliferation of MG-63 cells and MG-63/CDDP cells, and enhanced the anti-proliferative ability of CDDP. miR-22 induced apoptosis and inhibited autophagy of MG-63 cells and MG-63/CDDP cells. Apoptosis-related genes, including caspase-3 and Bcl-2-associated $\mathrm{X}$ protein were upregulated, while B-cell lymphoma-2 was downregulated in
\end{abstract}

Correspondence to: Dr Shi-Bing Guo or Dr Wei Feng, Department of Orthopedic Surgery, Second Affiliated Hospital of Inner Mongolia Medical University, 1 Yinfang Avenue, Huimin, Hohhot, Inner Mongolia 010030, P.R. China

E-mail: guoshibing2017@sina.com

E-mail: 603261696@qq.com

${ }^{*}$ Contributed equally

Abbreviations: Atg5, autophagy protein 5; CDDP, cisplatin; LC3, microtubule-associated protein 1A/1B-light chain 3; MDC, monodansylcadaverine staining; miRNA/miR, microRNA; MTDH, metadherin; OS, osteosarcomas

Key words: microRNA-22, cisplatin, osteosarcoma cells, apoptosis, autophagy both cell lines transfected with the miR-22 mimic. Autophagy protein 5, beclin1 and microtubules-associated protein 1 light chain 3 were downregulated in both cell lines transfected with miR-22 mimic. Furthermore, the in vitro and in vivo expression levels of metadherin (MTDH) in the OS/OS-CDDP-resistant models were downregulated following transfection with the miR-22 mimic. Therefore, the results of the present study suggested that miR-22 promoted CDDP sensitivity by inhibiting autophagy and inducing apoptosis in OS cells, while MTDH may serve a positive role in inducing CDDP resistance of OS cells.

\section{Introduction}

Osteosarcoma (OS) is a type of primary malignant tumor of the bone that is characterized by the production of osteoid or immature bone by malignant cells $(1,2)$. OS is an uncommon tumor type. In total, 750-900 new cases are diagnosed each year in the USA, of which 400 arise in children and adolescents $<20$ years of age (3). Despite its rarity, OS is the most common primary malignancy of bone in children and adolescents, and the fifth most common malignancy among adolescents and young adults aged $15-19$ years $(3,4)$.

It has been shown that effective chemotherapy may improve the survival of patients with OS in numerous reports (5). The combination of surgical resection and multiple chemotherapy, including neoadjuvant therapy, has been standardized for the clinical treatment of patients with OS since 1970 (6). This regimen markedly ameliorates symptoms and extends the overall survival time of patients with OS (6). It has been reported that the combination of three types of chemotherapy, including methotrexate, doxorubicin and cisplatin (CDDP), has achieved a good outcome, particularly for children and young adults (5). As such, reducing drug resistance and improving drug sensitivity are significant issues for chemotherapy in OS.

Lee et al (7) first discovered microRNAs (miRNAs), endogenous small RNA molecules that can regulate $>30 \%$ of all human genes, and which have been shown to exhibit regulatory functions $(8,9)$. miRNAs bind to the 3'-untranslated region perfectly or imperfectly and lead to translational suppression or the degradation of various target mRNAs (10). Furthermore, it has been reported that miRNAs have regulatory roles in gene expression at the post-transcriptional level (11). miRNAs 
have been found to serve regulatory roles in tumorigenesis and chemosensitivity in various types of cancer (12). An increasing number of studies have concentrated on the role of miRNAs in OS drug resistance, with the aim of providing possibilities for improving the quality of life of patients with OS. Numerous reports have argued that miRNAs serve a significant role in OS drug resistance (13). miRNAs are associated with OS drug resistance through the DNA damage response, apoptosis avoidance, autophagy induction, activation of cancer stem cells and alteration of signaling pathways (14-17). Notably, it has been found that apoptosis is associated with death, while autophagy acts as a double-edged sword in malignant tumor cells (18). The role of autophagy in OS drug-resistance requires further investigation.

miRNA-22 (miR-22) is located on the $17 \mathrm{p} 13$ chromosome and serves crucial roles in tumor suppression in numerous malignancies, including breast and prostate cancers (19-21). A previous study found that miR-22 suppresses the proliferation and promotes the sensitivity of OS cells by inhibiting metadherin (MTDH)-mediated autophagy (22). MTDH upregulates multidrug resistance gene 1 expression levels and is associated with autophagy and chemoresistance (23). A recent report demonstrated that miR-22 inhibits the proliferation and migration of OS cells, as well as increasing their sensitivity to CDDP (24). However, the mechanisms of action of miR-22 in OS drug resistance, particularly with regards to drug-resistance, require further study. Furthermore, the association between apoptosis and autophagy, which are associated with miR-22 in OS drug resistance, requires defining, and more target genes associated with miR-22 need to be investigated. This present study aimed to investigate the roles of miR-22-regulated apoptosis and autophagy in OS CDDP resistance.

\section{Materials and methods}

Cell lines. Human OS cell lines, including MG-63, U2OS, Saos 2 were obtained from The Cell Bank of Type Culture Collection of the Chinese Academy of Sciences, Shanghai, China. OS9901 cells (25-28) were donated by the Department of Orthopedics, Tangdu Hospital, the Fourth Military Medical University, Xi'an, China. The cells were cultured in Dulbecco's modified Eagle's medium (DMEM; Hyclone; GE Healthcare) containing 10\% FBS (HyClone; GE Healthcare Life Sciences), $100 \mathrm{U} / \mathrm{ml}$ penicillin (HyClone; GE Healthcare Life Sciences) and $100 \mu \mathrm{g} / \mathrm{ml}$ streptomycin (HyClone; GE Healthcare Life Sciences), and incubated at $37^{\circ} \mathrm{C}$ with $5 \% \mathrm{CO}_{2}$. CDDP $(2 \mu \mathrm{M})$ was added to the cell lines for $24 \mathrm{~h}$. Next, reverse transcription-quantitative polymerase chain reaction (RT-qPCR) assays and western blotting were performed to investigate the expression levels of cleaved caspase- 3 and microtubule-associated protein 1A/1B-light chain 3 (LC3).

Cell culture and transfection. The drug resistant cells (MG-63/CDDP) were obtained by growing MG-63 cells in a 6 -well plate and adding $2 \mu \mathrm{M}$ CDDP for $24 \mathrm{~h}$. Dead cells were removed by phosphate-buffered saline (PBS). When the cells had reached $80 \%$ confluence, $2 \mu \mathrm{M}$ CDDP was added for $24 \mathrm{~h}$. This was repeated until CDDP no longer led to any further cell death. The final cells were deemed drug-resistant cells (MG-63/CDDP).
Lipofectamine ${ }^{\circledR} 3000$ (Invitrogen; Thermo Fisher Scientific, Inc.) was used for all transfection assays, according to the manufacturer's protocol. MG-63 cells and MG-63/CDDP cells were transiently transfected using negative control (NC) or miR-22 mimic (Shanghai GenePharma Co., Ltd.). The concentration of each miRNA transfected was $50 \mathrm{nM}$ per well. A total of $50 \mu \mathrm{l}$ Opti-MEM (Gibco; Thermo Fisher Scientific, Inc.) was used to dilute $50 \mathrm{nM}$ NC or mimic. The diluted NC and mimic solutions were mixed with $3 \mu$ Lipofectamine ${ }^{\circledR} 3000$ and incubated for $20 \mathrm{~min}$ at room temperature. This solution was incubated with the cells in a 6 -well plate $(100 \mu 1$ liposome transfection mixture per well). Following incubation for $6 \mathrm{~h}$, the medium was replaced with DMEM with 10\% fetal bovine serum (HyClone; Cytiva). After $48 \mathrm{~h}$ of incubation, the cells were harvested and centrifuged at $500 \mathrm{~g}$ for $5 \mathrm{~min}$ at room temperature.

The 5'-3' sequences of the NC and miR-22 mimic constructs were as follows: NC sense, UUCUCCGAACGUGUCACG UTT and antisense, ACGUGACACGUUCGGAGAATT; and miR-22 sense, AAGCUGCCAGUUGAAGAACUGU and antisense, AGUUCUUCAACUGGCAGCUUUU.

Cell proliferation assays. MG-63 and MG-63/CDDP cells (5,000 cells/well) were plated into 96-well plates, which were divided into MG-63 and MG-63/CDDP groups. The MG-63 groups consisted of a control group, a miR-22 group, a CDDP group and a CDDP + miR-22 group. The MG-63/CDDP groups also consisted of a control group, a miR-22 group, a CDDP group and a CDDP + miR-22 group. Each group was analyzed in triplicate. After the cells were adhered, the $2 \mu \mathrm{M}$ CDDP treatment was applied and the cells were incubated for 6,12 or $24 \mathrm{~h}$. A total of $10 \mu \mathrm{l}$ MTT $(5 \mathrm{mg} / \mathrm{ml})$ was added to each well and the plates were incubated for a further $3 \mathrm{~h}$. Finally, $150 \mu \mathrm{l}$ dimethyl sulfoxide (Sigma-Aldrich; Merck KGaA) was added to each well following removal of the medium. An absorbance microplate reader (Thermo Fisher Scientific, Inc.; Multiskan 51119000) was used to measure the absorbance at $570 \mathrm{~nm}$.

Apoptosis assays. The experimental cells were washed three times with PBS at. Centrifugation was performed at $500 \mathrm{x} \mathrm{g}$ for $5 \mathrm{~min}$ at $4^{\circ} \mathrm{C}$. The cells were then bathed with $1 \mathrm{ml}$ binding buffer and centrifuged $\left(500 \mathrm{x} \mathrm{g}, 5 \mathrm{~min}, 4^{\circ} \mathrm{C}\right)$. Binding buffer-suspended cells $(100 \mu \mathrm{l})$, and $5 \mu \mathrm{m}$ propidium iodide (eBioscience; Thermo Fisher Scientific, Inc.) and $5 \mu \mathrm{l}$ FITC-Annexin V (eBioscience; Thermo Fisher Scientific, Inc.) were added. The cells were uniformly mixed and then incubated at room temperature for $15 \mathrm{~min}$ in the dark. Binding buffer $(400 \mu 1)$ was added to the mixture. The cells were immediately analyzed by flow cytometry. Finally, the data and output reports were collected and analyzed. Following incubation for $24 \mathrm{~h}$, apoptosis assays was performed.

Flow cytometry assays. Following incubation for $24 \mathrm{~h}$, a flow cytometry assay was performed. Changes in the expression levels of the autophagy-related protein, LC3, were quantitatively evaluated using flow cytometry (BD Calibur flow cytometer; BD Biosciences). Cells were fixed with $4 \%$ paraformaldehyde for $10 \mathrm{~min}$ at $4^{\circ} \mathrm{C}$, followed by three washes with PBS (5 min each wash). PBS/1\% BSA solution was used for preparing a 1:500 dilution of the LC3 antibody. Subsequently, the cells were incubated for $2 \mathrm{~h}$ with the 
primary antibody (LC3, cat. no. ab229327; Abcam) at room temperature. The Alexa Fluor-488-conjugated secondary antibody (cat. no. A11008; Invitrogen; Thermo Fisher Scientific, Inc.) was dissolved in PBS/1\% BSA solution to 1:400 and then added to the fixed cells in the dark at room temperature for $1 \mathrm{~h}$. The treated cells were analyzed using flow cytometry on a BD FACSCalibur platform (BD Biosciences). Changes in cellular fluorescence were detected in the FL1 channel (BD Caliber, FACSCalibur; BD Biosciences).

The isotype control was stained with rabbit $\mathrm{IgG}$ (cat. no. ab172730; Abcam) under the aforementioned conditions. BSA was used for blocking unspecific protein.

$R T-q P C R$.TRIzol ${ }^{\circledR}$ reagent(Invitrogen; ThermoFisher Scientific, Inc.) was used to isolate total RNA from cells, according to the manufacturer's protocol. The PrimeScript RT Reagent kit (Takara Bio, Inc.) was used to convert RNA into cDNA. The condition of RT was $15 \mathrm{~min}$ at $37^{\circ} \mathrm{C}$ and $5 \mathrm{sec}$ at $85^{\circ} \mathrm{C}$. The miRNA Extraction kit (Guangzhou RiboBio Co., Ltd.) was used to convert miRNA into cDNA. Quantification of the transcript expression levels were obtained by performing qPCR using SYBR Premix Ex Taq (Takara Bio, Inc.). The ABI StepOne Plus Real-Time PCR system (Applied Biosystems; Thermo Fisher Scientific, Inc.) was used for qPCR using the SYBR-Green PCR kit (Takara Bio,Inc.). The qPCR protocol consists of the following steps: i) Initial denaturation for $5 \mathrm{~min}$ at $95^{\circ} \mathrm{C}$; and ii) 40 cycles involving denaturation at $95^{\circ} \mathrm{C}$ for $10 \mathrm{sec}$, followed by annealing and extension at $60^{\circ} \mathrm{C}$ for $34 \mathrm{sec}$. Each experiment was repeated three times. The miR-22 primers used were from the Bulgeloop miRNA qRT-PCR kit (Guangzhou RiboBio Co., Ltd.). Detailed information of the primers employed for the qPCR experiments is presented in Table I. The $2^{-\Delta \Delta \mathrm{Cq}}$ analysis method was used as quantification method (29).

Western blot analysis. The cells were washed with pre-chilled PBS and lysed in $200 \mu \mathrm{l}$ RIPA buffer (Beyotime Institute of Biotechnology) for $30 \mathrm{~min}$ on ice, followed by centrifugation at $13,500 \mathrm{x} \mathrm{g}$ at $4^{\circ} \mathrm{C}$ for $5 \mathrm{~min}$. Protein quantification was performed using a bicinchoninic acid protein quantification kit (Beyotime Institute of Biotechnology). Next, 10\% SDS-PAGE (Bio-Rad Laboratories, Inc.) was used to separate the cellular proteins (30 $\mu \mathrm{g} / \mathrm{sample})$, followed by blot transfer to a polyvinylidene difluoride membrane (EMD Millipore). Post-blotting, the membrane was incubated with $5 \%$ skimmed milk at $4^{\circ} \mathrm{C}$ for $1 \mathrm{~h}$. To prepare 1:1,000 dilutions of the primary antibodies, 5\% BSA-containing TBS/Tween-20 (TBST) solution was used, and the primary antibodies were incubated with the membrane overnight at $4^{\circ} \mathrm{C}$. The membranes were washed three times with TBST at room temperature (10 min each wash). The secondary antibody was diluted with TBST (1:5,000 dilution) and the membranes were further incubated with the secondary antibody at room temperature for $1 \mathrm{~h}$, followed by three washes with TBST at room temperature (10 min each wash). The chemiluminescence reaction was performed using the Tanon chemiluminescence sensor system (Tanon Science and Technology Co., Ltd.). GAPDH (cat. no. 200306-7E4; Zen-BioScience) was used as the loading control. The antibodies used in the western blot assays were as follows: Cleaved caspase-3 (cat. no. ab49822; Abcam), B-cell lymphoma-2 (Bcl-2; cat. no. 50599-2-Ig; ProteinTech Group,
Inc.), Bcl-2-associated X protein (Bax; cat. no. 12789-1-AP; ProteinTech), autophagy protein 5 (ATG5; cat. no. ab108327; Abcam), beclin1 (cat. no. ab207612; Abcam), LC3 (cat. no. ab229327; Abcam) and MTDH (cat. no. ab227981; Abcam). The secondary antibodies used were as follows: Horseradish peroxidase (HRP)-conjugated goat anti-mouse IgG (H+L; cat. no. A0216, Beyotime Institute of Biotechnology) and HRP goat anti-rabbit IgG (H+L; cat. no. A0208; Beyotime Institute of Biotechnology). The LC3 protein quantification was defined as the ratio of LC3 II to LC3 I.

Inoculation of tumor cells. Tumors used in the present study were the ones obtained from our previous study (30). The detailed information is as follows: To obtain the miR-22 overexpression vector, the pre-miR-22 hairpin was constructed in the pLV6-EF-1Af/puro lentivirus plasmid (Shanghai GenePharma Co., Ltd.). The plasmid was co-transfected into 293T cells using Lipofectamine ${ }^{\circledR} 2000$ with the pG-P1-VSVG, pG-P2-REV or pG-P3-RRE plasmids. Following culture for $48 \mathrm{~h}$, the lentivirus particles were harvested and concentrated using the lenti-X concentrator (Clontech Laboratories, Inc.), according to the manufacturer's protocol. MG-63 and MG-63/CDDP cells were plated into 6-well plates. Following culture for $8 \mathrm{~h}$, the lentivirus particles were added to the plate to treat cells with a multiplicity of infection of 1:50. The stable clones were selected using $1 \mu \mathrm{g} / \mathrm{ml}$ puromycin for $\sim 1$ week (fluid was changed every three days).

All animal experiments were performed following the approval of the Inner Mongolia Medical University Animal Ethics Committee and according to the Guidelines for the Care and Use of Laboratory Animals. After 7 days of adaptive feeding, 48 male nude mice $\left(19.51 \pm 2.71 \mathrm{~g}, 25^{\circ} \mathrm{C}, 12 \mathrm{~h}\right.$ of light and $12 \mathrm{~h}$ of darkness every day, $200 \mathrm{ml}$ water per day, SPF-level animal house) aged 8-weeks (SCXK2015-0001) were randomly divided into the following 8 groups, with 6 mice in each group: i) MG63; ii) $\mathrm{MG63}+$ miR-22; iii) $\mathrm{MG} 63+$ CDDP; iv) MG63 + CDDP + miR-22; v) MG63/CDDP; vi) MG63/CDDP + miR-22; vii) MG63/CDDP + CDDP; and viii) MG63/CDDP + CDDP + miR-22. Subcutaneous injections of $5 \times 10^{6}(100 \mu \mathrm{l})$ cells in the right axilla were performed. The nude mice were fed normally with access to food and water ad libitum and after the appearance of small nodules (after 7 days of inoculation), the MG63, MG63 + miR-22, MG63/CDDP and MG63/CDDP + miR-22 groups were administered with a normal saline injection of $100 \mu \mathrm{l}$, twice per week for 5 weeks. CDDP injections were administered ( $2 \mathrm{mg} / \mathrm{kg}$ ) twice per week for 5 weeks to the MG63 + CDDP, MG63 + CDDP + miR-22, MG63/CDDP $+\mathrm{CDDP}$ and the MG63/CDDP + CDDP + miR-22 groups. The Animal health and behavior were monitored every day. Time was started when the forelimb underarm was injected with tumor cells using a syringe. Subsequently, the diameter of the tumor was measured twice a week, to ensure that the tumor did not exceed $1.5 \mathrm{~cm}$ length, and the nude mice were sacrificed after 6 weeks. No mice exhibited more than one tumor and the maximum tumor volume were as follows: $897.793 \mathrm{~mm}^{3}$ in the MG63 group, $490.469 \mathrm{~mm}^{3}$ in the MG63 + miR-22 group, $418.669 \mathrm{~mm}^{3}$ in the MG63 + CDDP group, $274.963 \mathrm{~mm}^{3}$ in the MG63 + miR-22 + CDDP group, $964.291 \mathrm{~mm}^{3}$ in the MG63/CDDP group, $749.117 \mathrm{~mm}^{3}$ 
Table I. Detailed information of primers for the quantitative polymerase chain reaction experiments.

\begin{tabular}{lll}
\hline Gene & \multicolumn{1}{c}{ Sense } & \multicolumn{1}{c}{ Anti-sense } \\
\hline GAPDH & CTTTGGTATCGTGGAAGGACTC & AGTAGAGGCAGGGATGATGT \\
Caspase-3 & CTCCACAGCACCTGGTTATT & AAATTCAAGCTTGTCGGCATAC \\
Bcl-2 & GGAGGATTGTGGCCTTCTTT & GTTCAGGTACTCAGTCATCCAC \\
Bax & GGAGCTGCAGAGGATGATTG & AGTTGAAGTTGCCGTCAGAA \\
Beclin1 & GCAGCTGGATAAGCTGAAGA & CGACCCAGCCTGAAGTTATT \\
Atg5 & TGACAAAGATGTGCTTCGAGAT & AGTATGGTTCTGCTTCCCTTTC \\
LC3 & GACATCTACGAGCAGGAGAAAG & TCAGAAGCCGAAGGTTTCC
\end{tabular}

GAPDH, glyceraldehyde; Bcl-2, B-cell lymphoma-2; Bax, Bcl-2-associated X protein; Atg5, autophagy protein 5; LC3, microtubules-associated protein 1-light chain 3 .

in the MG63/CDDP + miR-22 group, $456.618 \mathrm{~mm}^{3}$ in the MG63/CDDP + CDDP group and $303.634 \mathrm{~mm}^{3}$ in MG63/CDDP + miR-22 + CDDP group.

When nude mice were loaded with a tumor or injected with cisplatin, the nude mice were anesthetized using isoflurane gas. Following the operation, the nude mice were placed in the cage for normal feeding. Samples were collected after 6 weeks of normal feeding. A dose of $1.5 \%$ isoflurane was used for anesthesia. The dose of pentobarbital administered was $100 \mathrm{mg} / \mathrm{kg}$ and the method of euthanasia was intraperitoneal injection. After 10 min of intraperitoneal administration of pentobarbital, the tumor tissue was removed following the absence of respiration, heartbeat, corneal reflex, muscle tone and mucosal color. Forty nude mice were sacrificed 6 weeks after tumor cell tumor bearing, none of nude mice died during the 6 weeks. The tumor growth was shown in our previous study (30).

Immunohistochemistry. Samples were fixed with $4 \%$ paraformaldehyde at room temperature for $48 \mathrm{~h}$. Paraffin-embedded sections $(4 \mu \mathrm{m})$ were placed in an oven at $65^{\circ} \mathrm{C}$ for $2 \mathrm{~h}$, dewaxed with water and washed with PBS three times, for 5 min each wash. The dehydration box was put into the lifting basket and dehydrated with $75 \%$ ethanol for $4 \mathrm{~h}, 85 \%$ ethanol for $2 \mathrm{~h}$, $90 \%$ ethanol for $2 \mathrm{~h}, 95 \%$ ethanol for $1 \mathrm{~h}$, anhydrous ethanol I for $30 \mathrm{~min}$, anhydrous ethanol II for $30 \mathrm{~min}$, alcohol benzene for 5-10 $\mathrm{min}$, -xylene I for 5-10 $\mathrm{min}$, xylene II for 5-10 $\mathrm{min}$, Wax I for 5-10 min, Wax II for $1 \mathrm{~h}$ and wax III for $1 \mathrm{~h}$. The slices were placed in EDTA buffer and microwaved for antigen retrieval. The EDTA buffer was boiled over medium heat for, allowed to cool for $10 \mathrm{~min}$ and then boiled again over low heat. The slices were placed in 3\% hydrogen peroxide solution (Sinopharm Chemical Reagent Co., Ltd.) and incubated at room temperature for $10 \mathrm{~min}$ to block endogenous peroxidase activity. PBS washes were performed three times, each time for $5 \mathrm{~min}$. The samples were blocked using 5\% BSA for $20 \mathrm{~min}$ at room temperature. BSA was then removed and $50 \mu l$ diluted primary antibodies (1:100) were added, ensuring to cover the tissue on each slice, and samples were incubated overnight at $4^{\circ} \mathrm{C}$. Subsequently, the samples were washed with PBS solution, followed by the addition of 50-100 $\mu 1$ secondary antibody to each section and incubation at $4{ }^{\circ} \mathrm{C}$ for $50 \mathrm{~min}$. A total of 50-100 $\mu \mathrm{l}$ fresh DAB (Sinopharm Chemical Reagent Co., Ltd.) was then added to each slice and the color development was visualized under an Upright Metallurgical light microscope (Nikon Corporation) at x200 magnification. After the color development was complete, the samples were rinsed with distilled water, counterstained with hematoxylin (5 min, room temperature), dehydrated with $1 \%$ hydrochloric acid alcohol (1 sec), rinsed with tap water, turned back/blue with ammonia and then rinsed with running water. The sections were subjected to a gradient of ethanol (70-100\%) for $10 \mathrm{~min}$ to dehydrate and dry the samples, followed by the addition of xylene (Sinopharm Chemical Reagent Co., Ltd.). The samples were then sealed with neutral gum (Sinopharm Chemical Reagent Co., Ltd.).

The antibodies used in the immunohistochemistry analyses were as follows: ATG5 (cat. no. ab108327; Abcam), beclin1 (cat. no. ab207612; Abcam), LC3 (cat. no. ab229327; Abcam) and MTDH (cat. no. ab227981; Abcam).

Statistical analysis. Each experiment was performed three times and the results are shown as the mean \pm standard deviation. SPSS 17.0 software (SPSS, Inc.) was used for statistical analysis. Differences among three or more groups were compared using one-way analysis of variance followed by Tukey's post hoc test for comparisons of the data between the groups. $\mathrm{P}<0.05$ was considered to indicate a statistically significant difference.

\section{Results}

Expression of apoptosis and autophagy-related genes is highest in the MG-63 cells, compared with the other cell lines. As presented in Fig. 1, the mRNA and protein expression levels of the apoptosis-related gene, caspase-3, and the autophagy-related gene, LC3, were significantly higher in MG-63 cells than in other cell lines, including U2OS, Saos2 and OS9901 $(\mathrm{P}<0.05)$.

miR-22 inhibits the proliferation of MG-63 cells and $M G-63 / C D D P$ cells and enhances the anti-proliferative ability of $C D D P$. MTT assays revealed that the cell proliferation ability decreased gradually with increasing treatment time in MG-63 cells and MG-63/CDDP cells (Fig. 2). Furthermore, cell proliferation was significantly suppressed in the miR-22 transfected group compared with the control group in both MG63 and MG63/CDDP cells $(\mathrm{P}<0.01)$. As presented in Fig. 2, the miR-22 + CDDP subgroup exhibited a significant decrease 

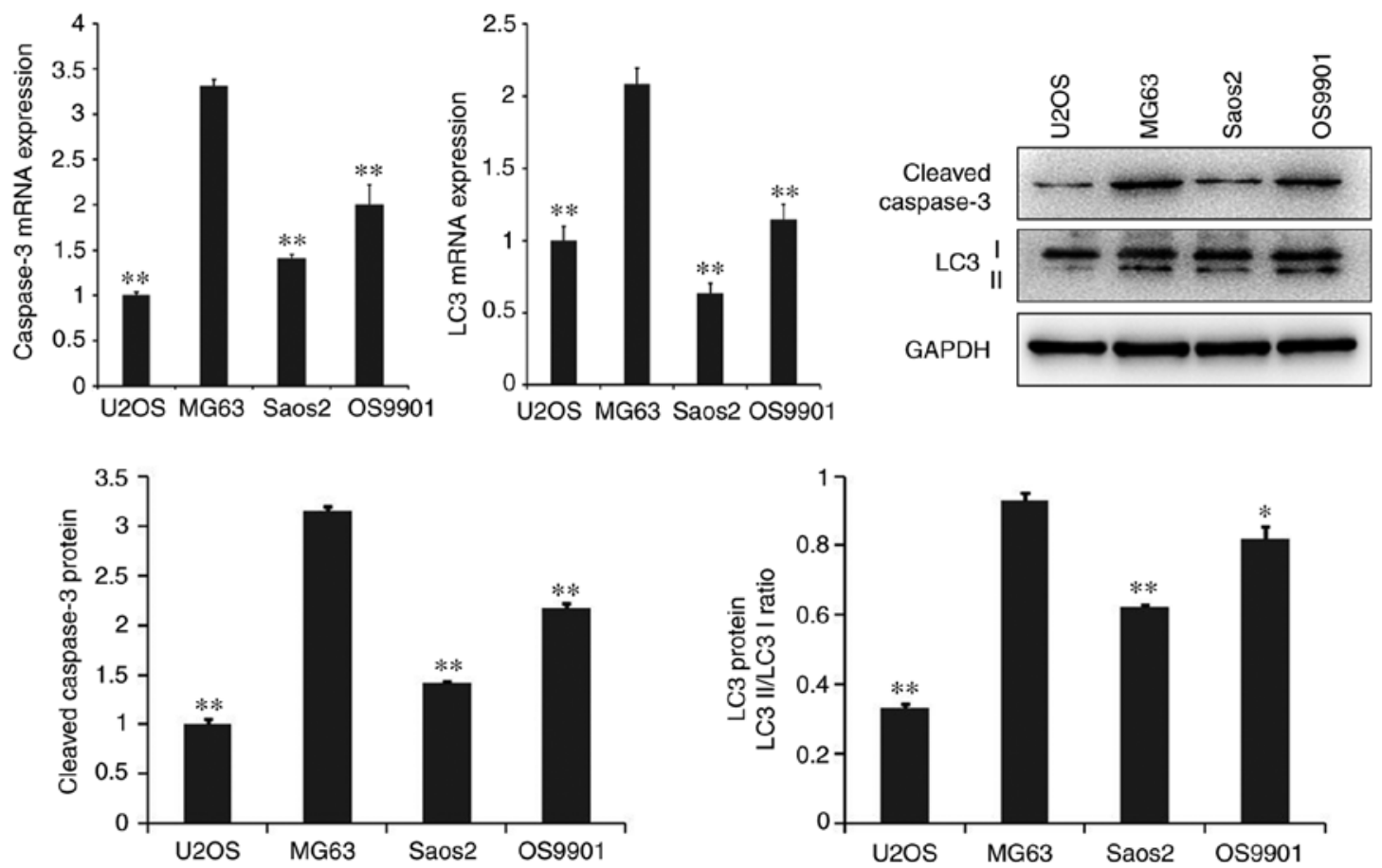

Figure 1. mRNA and protein expression levels of cleaved caspase-3 and LC3 in each cell line treated with CDDP. ${ }^{* *} \mathrm{P}<0.01$ vs. the MG63 control group. ${ }^{*} \mathrm{P}<0.05$, ${ }^{* *} \mathrm{P}<0.01$. LC3, microtubule-associated protein 1A/1B-light chain 3; CDDP, cisplatin.

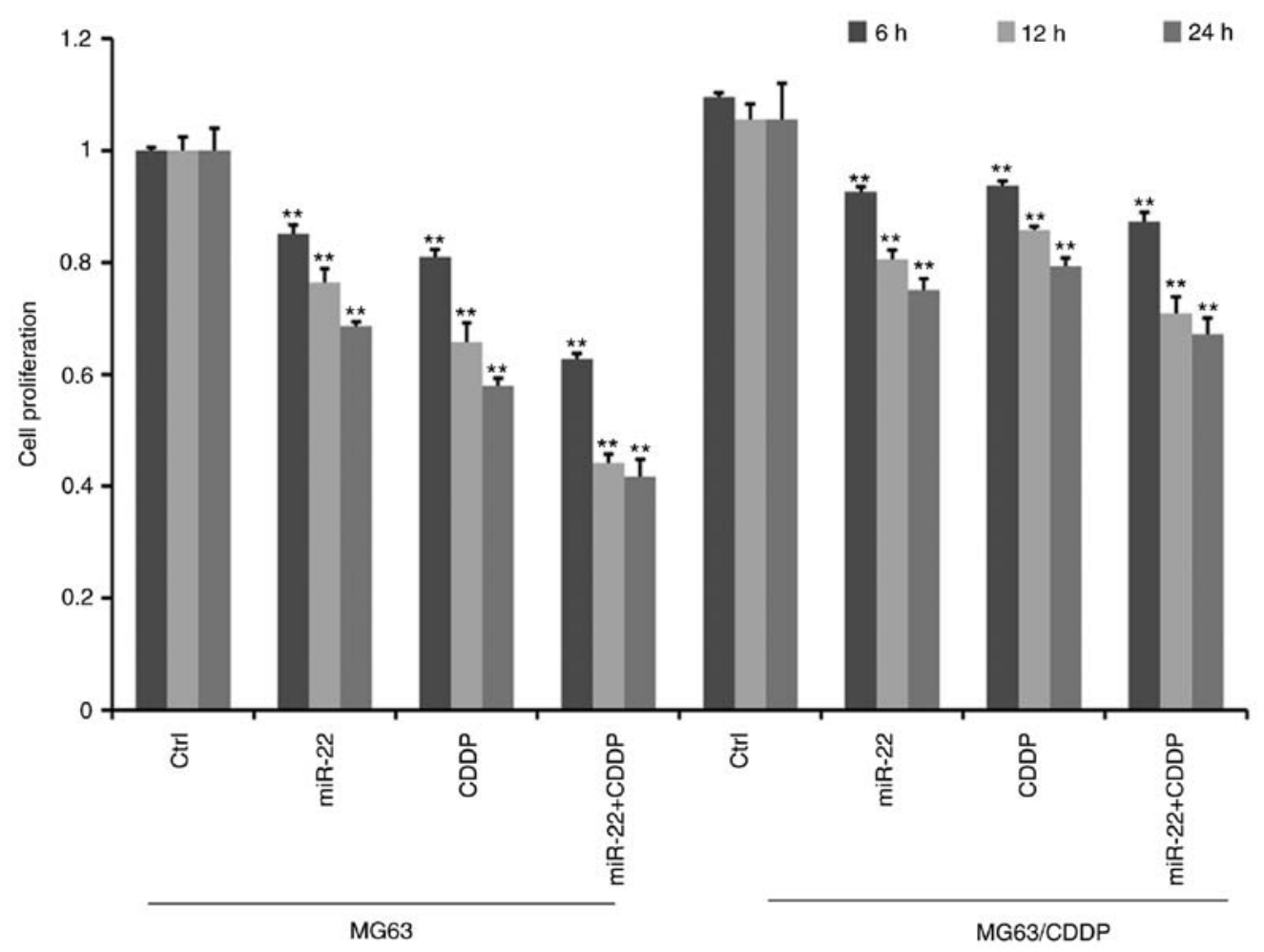

Figure 2. Cell proliferative ability of MG-63 and MG-63/CDDP cells following treatment with CDDP or miR-22 mimic. Optical densities are expressed as the mean \pm standard deviation. MG-63 proliferation was inhibited by miR-22 overexpression and CDDP in MG-63 and MG-63/CDDP cells. miR-22 overexpression enhanced the inhibition of CDDP. ${ }^{* *} \mathrm{P}<0.01$. CDDP, cisplatin; miR, microRNA.

in proliferative capacity compared with the other subgroups, both in MG-63 cells and MG-63/CDDP cells at each time point of 6,12 and $24 \mathrm{~h}(\mathrm{P}<0.01)$, which suggested that miR-22 enhanced CDDP sensitivity in MG-63 cells and that miR-22 decreased the drug resistance in MG-63/CDDP cells.
miR-22 induces apoptosis of $M G-63$ cells and $M G-63 / C D D P$ cells. The results of the apoptosis assay are presented in Fig. 3A and B. The apoptosis assay was performed using an Annexin V-FITC kit. It was demonstrated that miR-22-overexpression and CDDP treatment significantly 

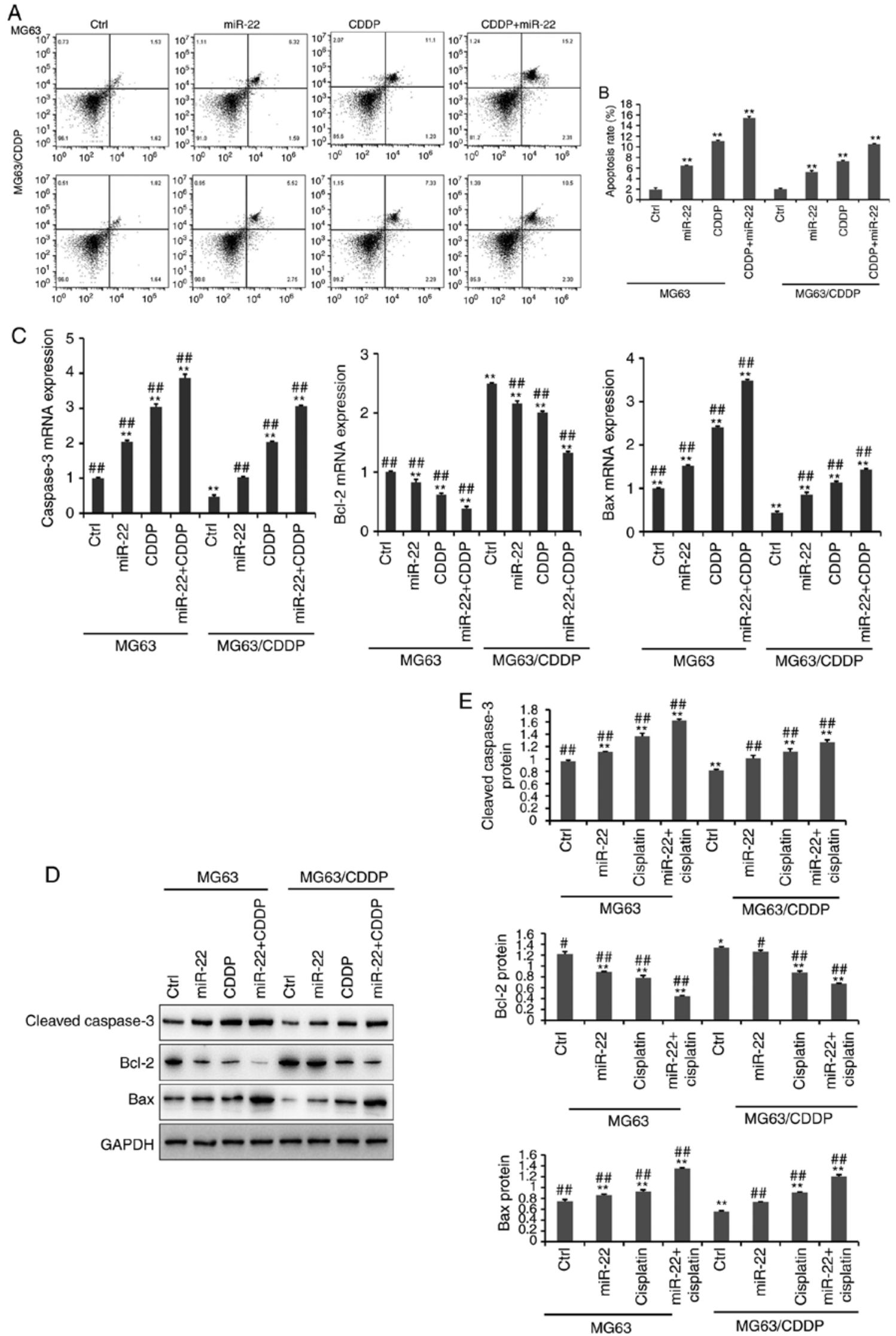

Figure 3. The results of cell apoptosis (A-E). (A) Cell apoptosis in MG-63 and MG-63/CDDP cells at $24 \mathrm{~h}$. The upper left quadrant represents dead cells, the lower left quadrant represents normal living cells, the lower right quadrant represents early apoptotic cells and the upper right quadrant represents late apoptotic cells. The percentage of cells in the upper right quadrant was calculated. (B) The rate of apoptosis is expressed as the mean \pm standard deviation. (C) The mRNA expression levels of the apoptosis-related genes, caspase-3, Bcl-2 and Bax. (D and E) The protein expression levels of the apoptosis-related genes, cleaved caspase-3, Bcl-2 and Bax, as determined by western bolt analyses. All protein bands were produced from the same membrane and as a result they have the same loading control. The data are presented as the mean \pm standard deviation. ${ }^{*} \mathrm{P}<0.05,{ }^{\text {*** }} \mathrm{P}<0.01$ vs. the MG- 63 control group; ${ }^{\#} \mathrm{P}<0.05$, ${ }^{\# \#} \mathrm{P}<0.01$ vs. the MG-63/CDDP control group. CDDP, cisplatin; Bcl-2, B-cell lymphoma-2; Bax, Bcl-2-associated X protein. 
A

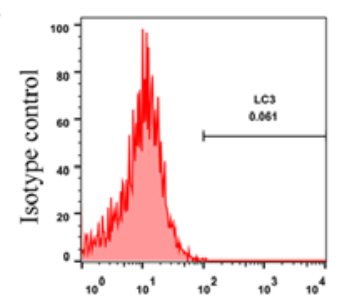

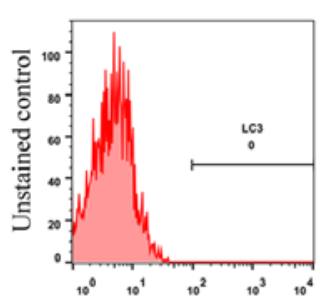

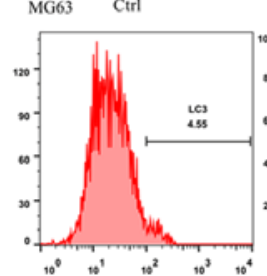

miR-22
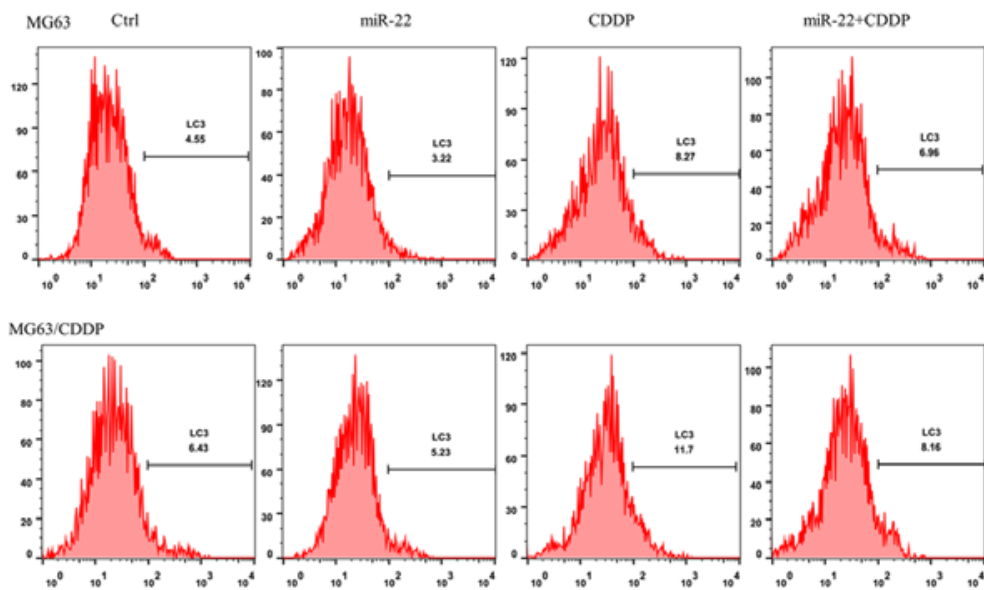

E

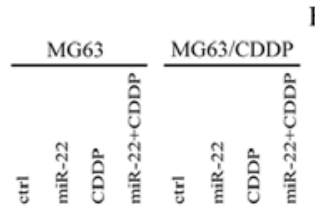

$\mathrm{F}$
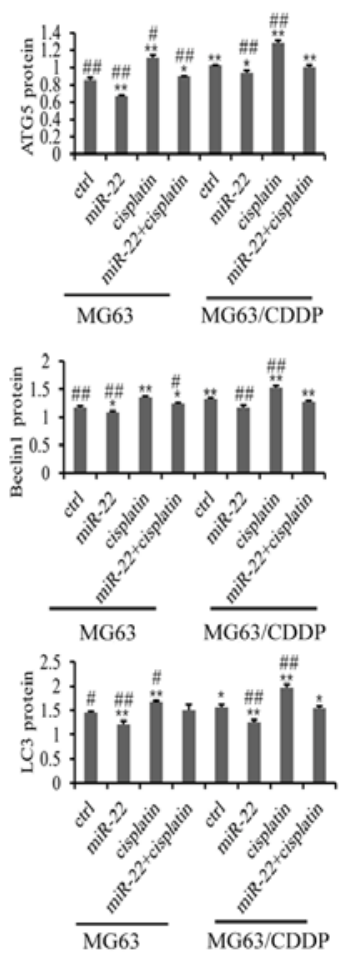

C

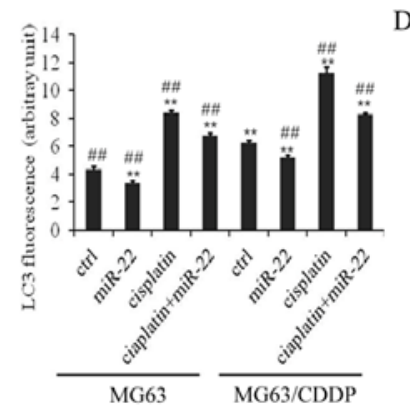

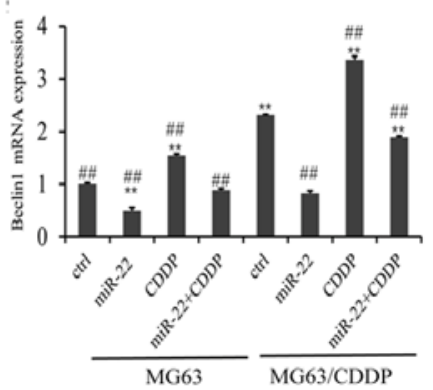
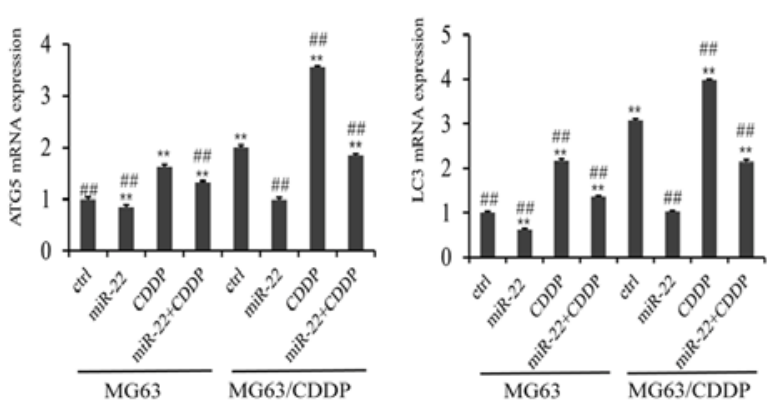

Figure 4. Flow cytometric analysis (A-F). (A) Isotype control for detecting the expression levels of LC3. (B) Flow cytometry of LC3 following transfection for $24 \mathrm{~h}$. (C) LC3 expression fluorescence values following transfection for $24 \mathrm{~h}$. (D) mRNA expression levels of the autophagy-related genes, ATG5, beclin1 and LC3. (E) and (F) The protein expression levels of the autophagy genes, ATG5, beclin1 and LC3, followed by western bolt analysis. All protein bands were produced from the same membrane and as a result they have the same loading control. Data is presented as the mean \pm standard deviation. ${ }^{*} \mathrm{P}<0.05,{ }^{* *} \mathrm{P}<0.01$ vs. the MG-63 control group; ${ }^{\#} \mathrm{P}<0.05,{ }^{\#} \mathrm{P}<0.01$ vs. the MG-63/CDDP control group. ATG, autophagy protein 5; LC3, microtubules-associated protein 1-light chain 3 .

induced cell apoptosis, compared with the untreated cells in MG-63 cells and MG-63/CDDP cells $(\mathrm{P}<0.01)$. In line with the results of the MTT assays, the miR-22 + CDDP subgroup in the MG-63 cells and MG-63/CDDP cells had the highest apoptosis rate at $24 \mathrm{~h}(\mathrm{P}<0.01)$. It was revealed that miR-22 enhanced CDDP sensitivity and decreased drug resistance by inducing cell apoptosis.

Further experiments demonstrated that the expression levels of apoptosis-related genes, including cleaved caspase-3, Bcl-2 and Bax, at the mRNA and protein level (Fig. 3C-E); MG-63/CDDP cells exhibited an upregulation of cleaved caspase-3 and Bax, and downregulation of Bcl-2 $(\mathrm{P}<0.01)$. The expression levels of cleaved caspase- 3 and Bax increased gradually in the control, miR-22, CDDP and miR-22 + CDDP subgroups (all $\mathrm{P}<0.01$ ), while Bcl-2 was downregulated. The results were the same in the MG-63 cells and MG-63/CDDP cells $(\mathrm{P}<0.01)$. The combination of miR-22 and CDDP demonstrated the most efficient ability to induce apoptosis by regulating the aforementioned genes $(\mathrm{P}<0.01)$.

miR-22 inhibits autophagy of $M G-63$ cells and $M G-63 / C D D P$ cells. The results of the LC3 flow cytometry assay are presented in Fig. 4A. As shown in Fig. 4B, the LC3 fluorescence value in the miR-22 group of the MG-63 and MG-63/CDDP cells was smaller than in each control group, while the value was higher in the CDDP group of the two cell lines, which revealed that miR-22 inhibited autophagy and that CDDP induced autophagy $(\mathrm{P}<0.01)$. miR-22 decreased the autophagy induced by CDDP in MG-63 and MG-63/CDDP cells $(\mathrm{P}<0.01)$.

The mRNA and protein expression levels of the autophagy-related genes, ATG5, beclin1 and LC3, are shown in Fig. 4C-E. It was demonstrated that miR-22-overexpression downregulated the mRNA and protein expression levels of ATG5, beclin1 and LC3, while CDDP induced the expression of ATG5, beclin1 and LC3 in the MG-63 cells and 

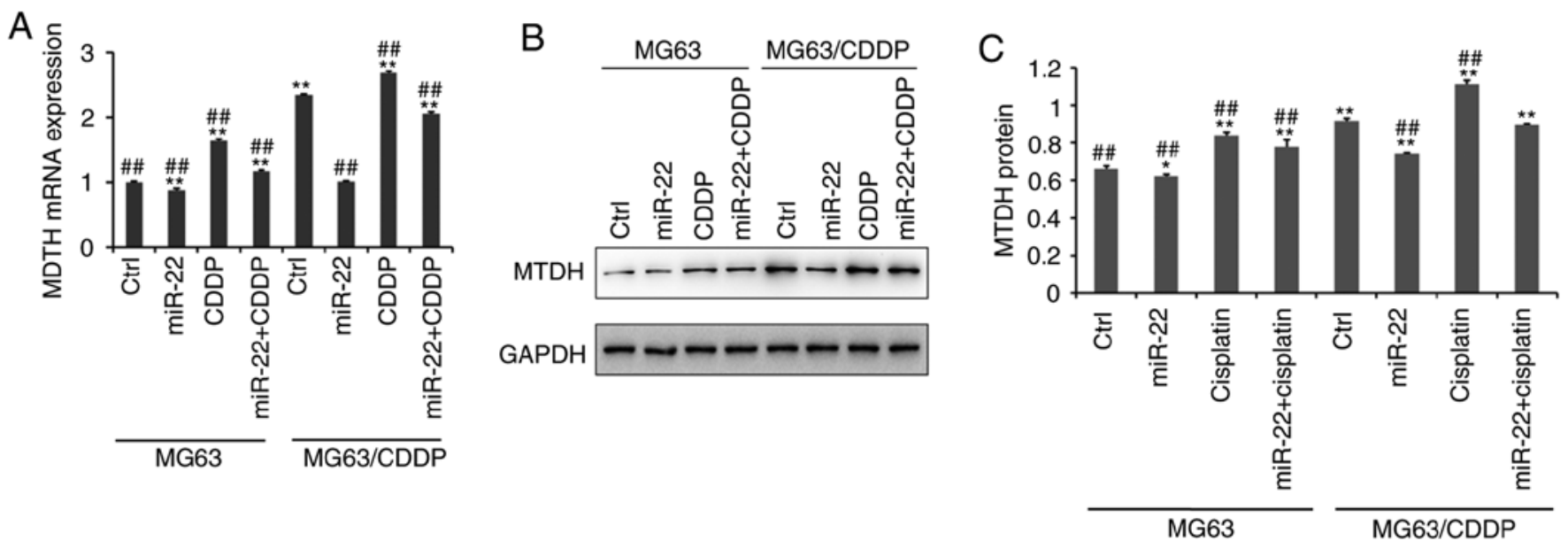

Figure 5. Reverse transcription-quantitative PCR and western blot assays of MTDH in MG63 cells and MG63/CDDP cells (A-C). (A) The mRNA expression of MTDH. (B and C) The protein expression of MTDH. All protein bands were produced from the same membrane and as a result they have the same loading control. ${ }^{*} \mathrm{P}<0.05,{ }^{* *} \mathrm{P}<0.01$ vs. the MG63 control group. ${ }^{\# \#} \mathrm{P}<0.01$ vs. the MG63/CDDP control group. MTDH, metadherin; CDDP, cisplatin.

MG-63/CDDP cells $(\mathrm{P}<0.01)$. Furthermore, miR-22 inhibited CDDP-induced autophagy in the MG-63 cells and MG-63/CDDP cells. These results suggested that miR-22 could enhance CDDP sensitivity and decrease drug resistance through inhibiting cell autophagy.

miR-22 downregulates MTDH to improve the sensitivity of $C D D P$ and to decrease drug resistance. Fig. $5 \mathrm{~A}$ demonstrates that the mRNA expression level of MTDH was downregulated following transfection with miR-22 mimic in MG-63 cells and MG-63/CDDP cells, whereas CDDP upregulated the expression of MTDH $(\mathrm{P}<0.01)$, particularly in the drug-resistant cell line. At the protein level, as shown in Fig. 5B and C, the expression level of MTDH was downregulated by miR-22 mimic in MG-63 cells and MG-63/CDDP cells $(\mathrm{P}<0.05)$. Additionally, at the mRNA and protein level, miR-22 may serve a role in inhibiting CDDP-induced MTDH upregulation to increase the sensitivity to CDDP and to decrease the drug resistance $(\mathrm{P}<0.05)$.

miR-22 regulates the expression of autophagy-related genes and MTDH in in vivo OS and OS drug resistance models. As shown in Fig. 6, the expression levels of Atg5, beclin1, LC3 and MTDH were downregulated by miR-22 mimic in MG-63 and MG-63/CDDP cells $(\mathrm{P}<0.05)$. The expression levels of these genes were further downregulated in the MG-63 cells, compared with the MG-63/CDDP cells $(\mathrm{P}<0.01)$. As in the in vitro model, in the in vivo model, CDDP upregulated the expression levels of Atg5, beclin1, LC3 and MTDH in the MG-63 and MG-63/CDDP groups $(\mathrm{P}<0.05)$.

\section{Discussion}

Effective chemotherapy may improve the survival of patients with OS. However, drug resistance is always a challenge for treatment. In the present study, the role of miR-22 in CDDP resistance was investigated. In the present study, it was demonstrated that miR-22 could inhibit the proliferation of MG-63 cells and MG-63/CDDP cells and enhance the anti-proliferative ability of CDDP treatment. miRNA decreased the drug-resistance ability in OS through affecting cell proliferation. Zou et al (31) reported that miR-133b induces chemoresistance of OS cells to CDDP treatment by promoting cell death, migration and invasion. Vanas et al (32) revealed that miR-21 could inhibit cell proliferation to increase chemosensitivity to antitumor drugs by targeting sprouty 2 . The present results were similar to a recent report by Zhou et al, which argued that miR-22 inhibits the proliferation and migration, as well as increasing the cisplatin-sensitivity of OS cells (24). In the present study, the mechanisms of action of miR-22 in drug-resistance cells were investigated, and it was demonstrated that miR-22 inhibited the proliferation of MG-63/CDDP cells. According to the present results, it can be verified that miR-22 may not only increase the CDDP sensitivity but also reduce the resistance of OS cells.

Apoptosis is considered to predict the treatment effect of anticancer drugs. Dysfunction of the normal apoptosis pathways may lead to uncontrolled cell proliferation, which can be seen in resistant cancer cells. Furthermore, the apoptotic process has been deemed an effective target to reverse cancer drug resistance (33). It has been reported that numerous miRNAs are associated with OS through cell apoptosis. Downregulation of miR-138 has been revealed in OS tissues and cell lines, with further research demonstrating that miR-138 transfection suppresses cell proliferation and induces cell apoptosis, as well as increasing drug responsiveness by binding to Enhancer Of Zeste Homolog 2 (34). It has been demonstrated that $\mathrm{Bcl}-2$ expression has a positive correlation with miR-21, which inhibits apoptosis and induces resistance to CDDP, while Bcl-2 siRNA may decrease the Bcl-2-induced resistance to CDDP (35). Additionally, miR-22 has been demonstrated to promote the apoptosis of OS cells through inducing cell cycle arrest (36). In the present study, it was revealed that miR-22 induced the apoptosis of MG- 63 cells and MG-63/CDDP cells. Further experiments suggested that the expression levels of cleaved caspase- 3 and Bax increased 
A

A $\quad$ MG63 MG63+miR-22 MG63+CDDP MG63+CDDP+ B
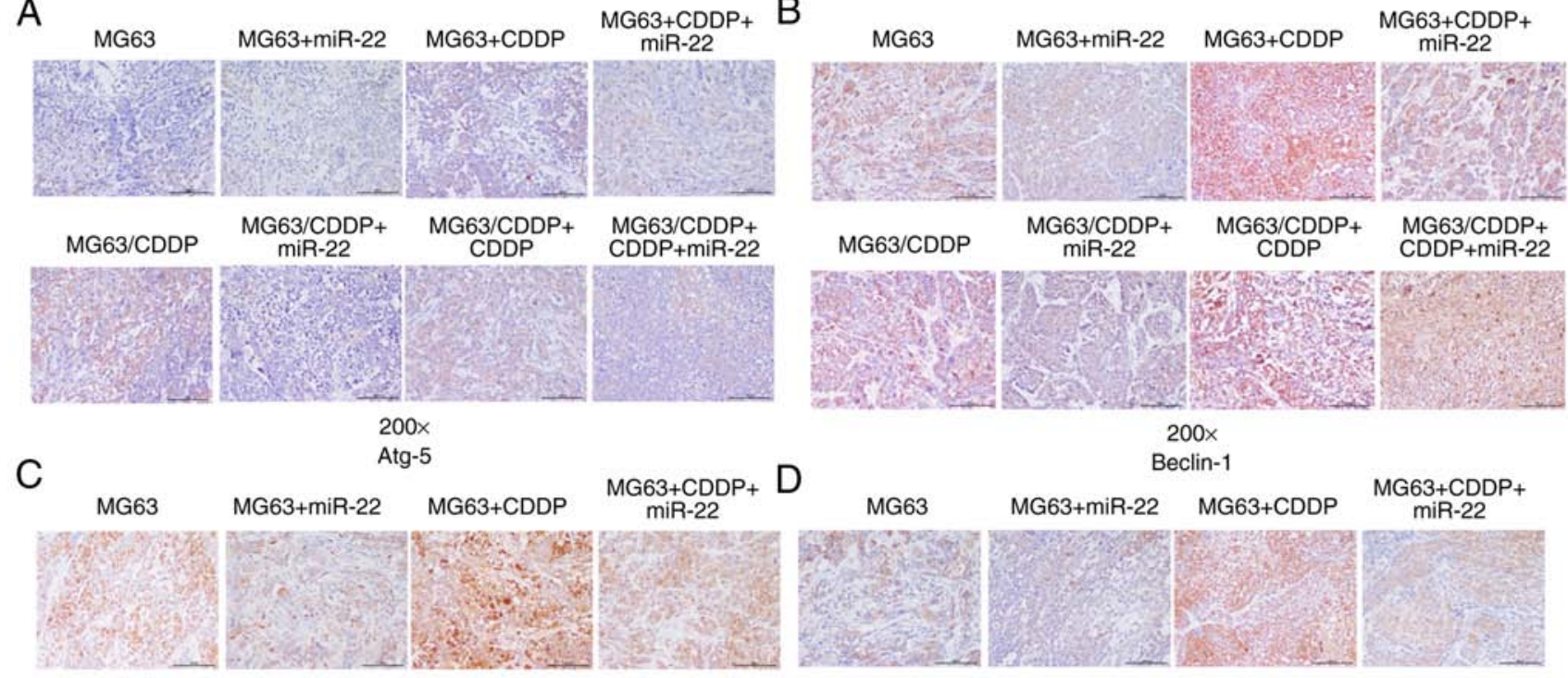

$200 \times$
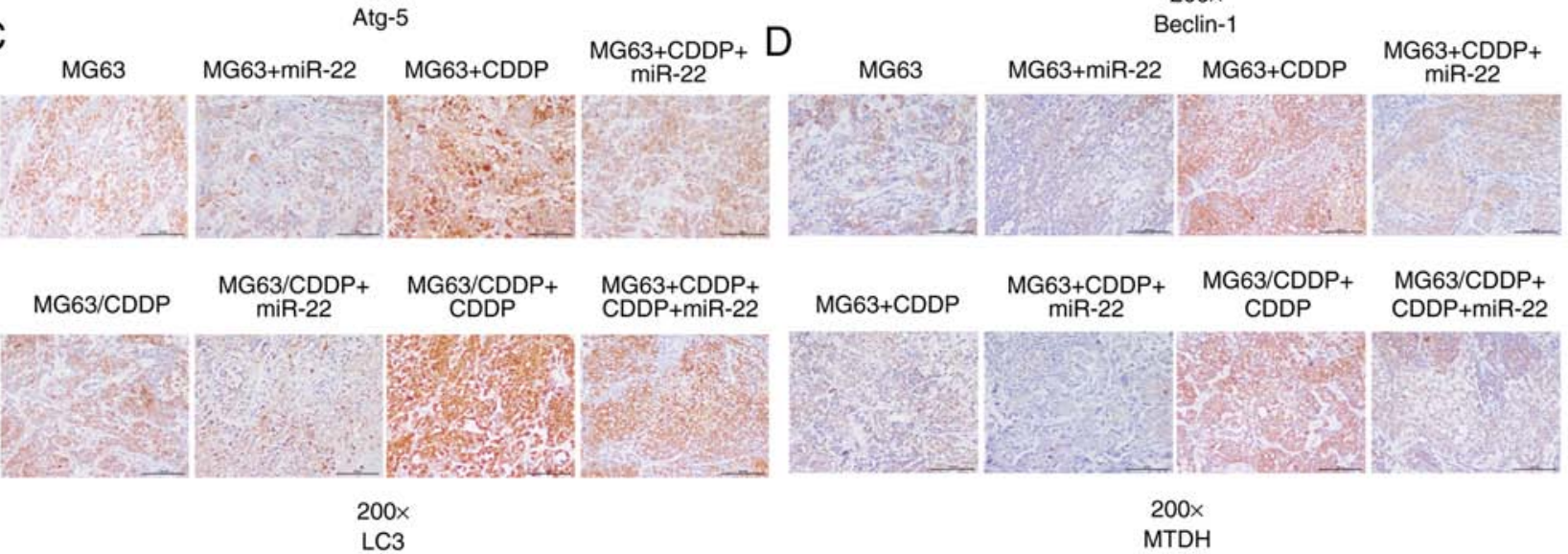

$\mathrm{E}$
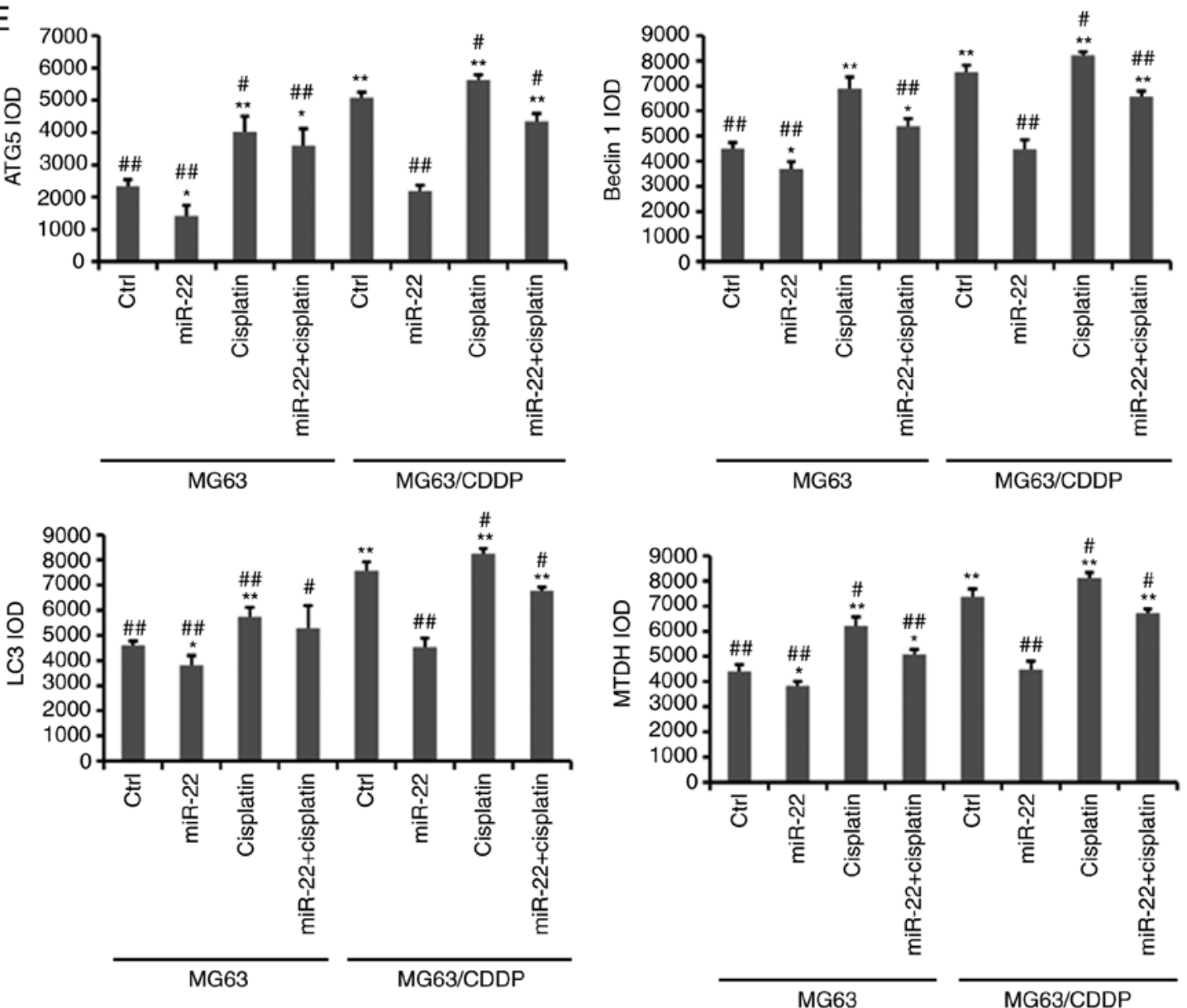

Figure 6. Immunohistochemistry results (A-E). (A) Immunohistochemical analysis of ATG5. (B) Immunohistochemical analysis of beclin1. (C) Immunohistochemical analysis of LC3. Magnification, $x 200$. (D) Immunohistochemical analysis of MTDH. (E) The immunohistochemical IOD values of ATG5, beclin1, LC 3 and MTDH following treatment of MG-63 cells and MG-63/CDDP cells. ${ }^{*} \mathrm{P}<0.05,{ }^{* *} \mathrm{P}<0.01$ vs. the MG-63 control group. ${ }^{\#} \mathrm{P}<0.05$, ${ }^{\# \#} \mathrm{P}<0.01$ vs. the MG-63/CDDP control group. ATG5, autophagy protein 5; MTDH, metadherin; LC3, microtubule-associated protein 1A/1B-light chain 3. 
gradually in the control, miR-22, CDDP and miR-22 + CDDP subgroups, while Bcl-2 was shown to be downregulated. The present study confirmed that miR-22 may enhance the CDDP sensitivity and decrease the drug resistance through inducing cell apoptosis.

In the present study, the autophagy-related genes, ATG5, beclin1 and LC3, were downregulated by miR-22 overexpression in MG-63/CDDP cells, which was consistent with the conclusions drawn from a previous study, which reported that miR-22 decreased the expression of ATG5, beclin1 and LC3 in MG-63 cells (22). The present study further verified that miR-22 could reduce CDDP resistance by inhibiting autophagy. It has been reported that miR-22 may target HMGB1-suppressed autophagy to reduce adriamycin and CDDP resistance $(15,37)$. MTDH has been reported to be associated with autophagy. The overexpression of MTDH induces autophagy, while downregulation of MTDH suppresses autophagy $(38,39)$. However, it has also been found that the simultaneous inhibition of autophagy and overexpression of MTDH decreases the levels of P-gp and inhibits 5-FU resistance (40). A previous study has reported that miR-22-overexpressing OS cells treated with CDDP demonstrated a significant decrease in the extent of autophagy from MDC staining. In this present study, it was further verified that miR-22 directly targeted the expression of MTDH in MG-63 cells. Furthermore, it was revealed that miR-22 may serve a role in inhibiting CDDP-induced MTDH upregulation, to increase the sensitivity to CDDP and to decrease drug resistance, which may aid in providing a new target gene to reduce CDDP resistance.

In conclusion, it was demonstrated in the present study that miR-22 could regulate CDDP sensitivity and decrease CDDP resistance by inhibiting autophagy and inducing apoptosis of OS cells and drug-resistant cells. The mechanism of action behind these effects may involve the inhibition of MG-63 and MG-63/CDDP cell proliferation, as well as through enhancing the anti-proliferative ability of CDDP treatment by apoptosis. Furthermore, miR-22 inhibited CDDP-induced MTDH upregulation and downregulated the expression levels of MTDH. The tumor formation experiments in vivo, and the detailed autophagy pathways associated with miR-22 in OS CDDP resistance require further study. The present study provided new insights for anti-chemoresistance in OS, contributing to the development of potential new therapeutic drugs for treating OS.

\section{Acknowledgements}

Not applicable.

\section{Funding}

The present study was supported by the National Natural Science Foundation of China (grant no. 81660440) and the Natural Science Foundation of Inner Mongolia (grant no. 2018MS08031).

\section{Availability of data and materials}

The datasets used and/or analyzed during the current study are available from the corresponding author on reasonable request.

\section{Authors' contributions}

CYM, ZQZ, SBG, WF, CS and YXW participated in the design of the study and drafted the manuscript. RB, LS and WZ collected the data and performed the statistical analyses. CYM, ZQZ, SBG and WF were major contributors to the design of this study and revised the manuscript. All authors read and approved the manuscript and agree to be accountable for all aspects of the research in ensuring that the accuracy or integrity of any part of the work are appropriately investigated and resolved.

\section{Ethics approval and consent to participate}

All animal experiments were performed following the approval of the Inner Mongolia Medical University Animal Ethics Committee and according to the Guidelines for the Care and Use of Laboratory Animals.

\section{Patient consent for publication}

Not applicable.

\section{Competing interests}

The authors declare that they have no competing interests.

\section{References}

1. Sissons HA: The WHO classification of bone tumors. Recent Results Cancer Res 54: 104-108, 1976.

2. Mckenna R: Sarcomata of the osteogenic series (osteosarcoma, fibrosarcoma, chondrosarcoma, parosteal osteogenic sarcoma, and sarcomata arising in abnormal bone): An analysis of 552 cases. J Bone Joint Surg Am 48: 1-26, 1966.

3. Ries LAG, Smith MA, Gurney JG, Linet M, Tamra T, Young JL and Bunin GR (eds.): Cancer incidence and survival among children and adolescents: United States SEER Program, 1975-1995, Bethesda, MD, 1999.

4. Stiller CA, Bielack SS, Jundt G and Steliarova-Foucher E: Bone tumours in European children and adolescents, 1978-1997. Report from the automated childhood cancer information system project. Eur J Cancer 42: 2124-2135, 2006.

5. Anninga JK, Gelderblom H, Fiocco M, Kroep JR, Taminiau AH, Hogendoorn PC and Egeler RM: Chemotherapeutic adjuvant treatment for osteosarcoma: Where do we stand? Eur J Cancer 47: 2431-2445, 2011.

6. Marina N, Gebhardt M, Teot L and Gorlick R: Biology and therapeutic advances for pediatric osteosarcoma. Oncologist 9: 422-441, 2004.

7. Lee RC, Feinbaum RL and Ambros V: The C. elegans heterochronic gene lin-4 encodes small RNAs with antisense complementarity to lin-14. Cell 75: 843-854, 1993.

8. Bentwich I, Avniel A, Karov Y, Aharonov R, Gilad S, Barad O, Barzilai A, Einat P, Einav U, Meiri E, et al: Identification of hundreds of conserved and nonconserved human microRNAs. Nat Genet 37: 766-770, 2005.

9. Djebali S, Davis CA, Merkel A, Dobin A, Lassmann T, Mortazavi A, Tanzer A, Lagarde J, Lin W, Schlesinger F, et al: Landscape of transcription in human cells. Nature 489: 101-108, 2012.

10. Zhong $\mathrm{X}$, Coukos $\mathrm{G}$ and Zhang L: miRNAs in human cancer. J Pathol 223: 102-115, 2015.

11. He L and Hannon GJ: MicroRNAs: Small RNAs with a big role in gene regulation. Nat Rev Genet 5: 522-531, 2004.

12. Xie L, Jing R, Qi J, Lin Z and Ju S: Drug resistance-related microRNAs in hematological malignancies: Translating basic evidence into therapeutic strategies. Blood Rev 29: 33-44, 2015.

13. Torreggiani E, Roncuzzi L, Perut F, Zini N and Baldini N: Multimodal transfer of MDR by exosomes in human osteosarcoma. Int J Oncol 49: 189, 2016. 
14. Duan Z, Gao Y, Shen J, Choy E, Cote G, Harmon D, Bernstein K, Lozano-Calderon S, Mankin H and Hornicek FJ: miR-15b modulates multidrug resistance in human osteosarcoma in vitro and in vivo. Mol Oncol 11: 151-166, 2017.

15. Guo S, Bai R, Liu W, Zhao A, Zhao Z, Wang Y, Wang Y, Zhao W and Wang W: miR-22 inhibits osteosarcoma cell proliferation and migration by targeting HMGB1 and inhibiting HMGB1-mediated autophagy. Tumor Biol 35: 7025-7034, 2014.

16. Zhou J, Wu S, Chen Y, Zhao J, Zhang K, Wang J and Chen S: microRNA-143 is associated with the survival of ALDH1+CD133+ osteosarcoma cells and the chemoresistance of osteosarcoma. Exp Biol Med 240: 867-875, 2015.

17. Zhao G, Cai C, Yang T, Qiu X, Liao B, Li W, Ji Z, Zhao J, Zhao H, Guo M, et al: MicroRNA-221 induces cell survival and cisplatin resistance through PI3K/Akt pathway in human osteosarcoma. PLoS One 8: e53906, 2013.

18. Ouyang L, Shi Z, Zhao S, Wang FT, Zhou TT, Liu B and Bao JK: Programmed cell death pathways in cancer: A review of apoptosis, autophagy and programmed necrosis. Cell Prolif 90: 487-498, 2012

19. Lagos-Quintana M, Rauhut R, Lendeckel W and Tuschl T: Identification of novel genes coding for small expressed RNAs. Science 294: 853-858, 2001.

20. Knyazev EN, Samatov TR, Fomicheva KA, Nyushko KM, Alekseev BY and Shkurnikov MY: MicroRNA hsa-miR-4674 in hemolysis-free blood plasma is associated with distant metastases of prostatic cancer. Bull Exp Biol Med 161: 112-115, 2016.

21. Damavandi Z, Torkashvand S, Vasei M, Soltani BM, Tavallaei M and Mowla SJ: Aberrant expression of breast development-related MicroRNAs, miR-22, miR-132, and miR-212, in breast tumor tissues. J Breast Cancer 19: 148-155, 2016.

22. Wang P, Zhao ZQ, Guo SB, Yang TY, Chang ZQ, Li DH, Zhao W, Wang YX, Sun C, Wang Y and Feng W: Roles of microRNA-22 in suppressing proliferation and promoting sensitivity of osteosarcoma cells via metadherin-mediated autophagy. Orthop Surg 11: 285-293, 2019.

23. Wan L, Hu G, Wei Y, Yuan M, Bronson RT, Yang Q, Siddiqui J, Pienta KJ and Kang Y: Genetic ablation of metadherin inhibits autochthonous prostate cancer progression and metastasis. Cancer Res 74: 5336-5347, 2014

24. Zhou X, Natino D, Zhai X, Gao Z and He X: MicroRNA-22 inhibits the proliferation and migration, and increases the cisplatin sensitivity, of osteosarcoma cells. Mol Med Rep 17: 7209-7217, 2018

25. Li Y, Geng P, Jiang W, Wang Y, Yao J, Lin X, Liu J, Huang L, Su B and Chen H: Enhancement of radiosensitivity by 5-Aza-CdR through activation of $\mathrm{G} 2 / \mathrm{M}$ checkpoint response and apoptosis in osteosarcoma cells. Tumour Biol 35: 4831-4839, 2014.

26. Yang TM, Guo SF, Chen CR, Zhang XY and Li WG: Anti-Osteosarcom aeffects and mechanisms of 4-O-aminophenol-4'-demethylepipodophyllotoxin ether. J Pharm Pharmacol 60: 179-188, 2008.

27. Tang J, Shen L, Yang Q and Zhang C: Overexpression of metadherin mediates metastasis of osteosarcoma by regulating epithelial-mesenchymal transition. Cell Prolif 47: 427-434, 2014
28. Ye H, Lin J, Yao X, Li Y, Lin X and Lu H: Overexpression of long non-coding RNA NNT-AS1 correlates with tumor progression and poor prognosis in osteosarcoma. Cell Physiol Biochem 45: 1904-1914, 2018.

29. Zhao S, Chen C, Chang K, Karnad A, Jagirdar J, Kumar AP and Freeman JW: CD44 expression level and isoform contributes to pancreatic cancer cell plasticity, invasiveness, and response to therapy. Clin Cancer Res 22: 5592-5604, 2016.

30. Meng CY, Zhao ZQ, Bai R, Zhao W, Wang YX, Xue HQ, Sun L, Sun C, Feng W and Guo SB: MicroRNA-22 mediates the cisplatin resistance of osteosarcoma cells by inhibiting autophagy via the PI3K/Akt/mTOR pathway. Oncol Rep 43: 1169-1186, 2020.

31. Zou Y, Yang J, Wu J, Luo C and Huang Y: miR?133b induces chemoresistance of osteosarcoma cells to cisplatin treatment by promoting cell death, migration and invasion. Oncol Lett 15: 1097-1102, 2018

32. Vanas V, Haigl B, Stockhammer V and Sutterlüty-Fall H: MicroRNA-21 increases proliferation and cisplatin sensitivity of osteosarcoma-derived cells. PLoS One 11: e0161023, 2016.

33. Karpel-Massler G, Shu C, Chau L, Banu M, Halatsch ME, Westhoff MA, Ramirez Y, Ross AH, Bruce JN, Canoll P and Siegelin MD: Combined inhibition of Bcl-2/Bcl-xL and Usp9X/Bag3 overcomes apoptotic resistance in glioblastoma in vitro and in vivo. Oncotarget 6: 14507-14521, 2015.

34. Zhu Z, Tang J, Wang J, Duan G, Zhou L and Zhou X: miR-138 acts as a tumor suppressor by targeting EZH2 and enhances cisplatin-induced apoptosis in osteosarcoma cells. PLoS One 11: e0150026, 2016.

35. Ziyan W and Yang L: MicroRNA-21 regulates the sensitivity to cisplatin in a human osteosarcoma cell line. Ir J Med Sci 185: 85-91, 2016

36. Gai P, Sun H, Wang G, Xu Q and Jiang L: miR-22 promotes apoptosis of osteosarcoma cells via inducing cell cycle arrest. Oncol Lett 13: 2354-2358, 2017.

37. Li X, Wang S, Chen Y, Liu G and Yang X: miR-22 targets the 3' UTR of HMGB1 and inhibits the HMGB1-associated autophagy in osteosarcoma cells during chemotherapy. Tumor Biol 35: 6021-6028, 2014

38. Yan J, Zhang J, Zhang X, Li X, Li L, Li Z, Chen R, Zhang L, Wu J, Wang X, et al: AEG-1 is involved in hypoxia-induced autophagy and decreases chemosensitivity in T-cell lymphoma. Mol Med 24: 35, 2018.

39. Zou M,Zhu W, Wang L, Shi L and Hu G: AEG-1/MTDH-activated autophagy enhances human malignant glioma susceptibility to TGF- $\beta 1$-triggered epithelial-mesenchymal transition. Oncotarget 7: 13122-13138, 2016.

40. Pei G, Luo M, Ni X, Wu J, Wang S, Ma Y and Yu J: Autophagy facilitates metadherin-induced chemotherapy resistance through the AMPK/ATG5 pathway in gastric cancer. Cell Physiol Biochem 46: 847-859, 2018

This work is licensed under a Creative Commons Attribution-NonCommercial-NoDerivatives 4.0 International (CC BY-NC-ND 4.0) License. 